\title{
Mathematical Modelling of PV Module With multilevel 3-Ø inverter using SPWM technique for Grid application
}

\author{
Lunavath Hemsingh ${ }^{1}$ \\ ${ }^{1}$ (Power Electronics \& Automation, Neyveli Lignite Corporation Ltd, Tamilnadu, India)
}

\begin{abstract}
This paper presents a simple step-by-step procedure for the simulation of photovoltaic modules with Matlab/ Simulink as well as Grid connected system for considering Three phase multistring inverter with sinusoidal pulse width modulation control scheme. The single-diode equivalent circuit is employed in order to Investigate I-V and P-V characteristics of a solar module. This paper focuses on a Matlab/SIMULINK model of a photovoltaic cell and Grid connected system, considering three phase multistring inverter with SPWM control scheme to reduce harmonics in primary side and same was applied to grid with prediction of $P V$ cell behaviour under different physical and environmental parameters. The PV model is based on mathematical equations and is described through an equivalent circuit including a photocurrent source, a diode, a series resistor and a shunt resistor. The developed model can also be used to extract the physical parameters for a given solar PV cell as a function of temperature and solar radiation. Three PV strings are cascaded together in parallel configuration and connected to a five-level inverter to produce output voltage in five levels of Vdc. That was equivalent to the amplitude of the triangular carrier signal were used to generate PWM signals for the switches. The inverter offers much less total harmonic distortion and can operate at near-unity power factor.
\end{abstract}

Keywords: DC-DC Converter, Multilevel Inverter, PV Module, SPWM, proportional-integral (PI) current control, multistring.

\section{Introduction}

Solar energy in one form or another is the source of nearly all energy on the earth. Humans, like all other animals and plants, rely on the sun for warmth and food. However, people also harness the sun's energy in many other different ways. For example, fossil fuels, plant matter from a past geological age, is used for transportation and electricity generation and is essentially just stored solar energy from millions of years ago. Similarly, biomass converts the sun's energy into a fuel, which can then be used for heat, transport or electricity. Wind energy, used for hundred of years to provide mechanical energy or for transportation, uses air currents that are created by solar heated air and the rotation of the earth. Even hydroelectricity is derived from the sun. Hydropower depends on the evaporation of water by the sun, and its subsequent return to the Earth as rain to provide water in dams. Photovoltaic (often abbreviated as PV) are a simple and elegant method of harnessing the sun's energy. PV devices (solar cells) are unique in that they directly convert the incident solar radiation into electricity, with no noise, pollution or moving parts, making them robust, reliable and long lasting. Solar cells are based on the same principles and materials behind the communications and computer revolutions, and this CDROM covers the operation, use and applications of photovoltaic devices and systems.

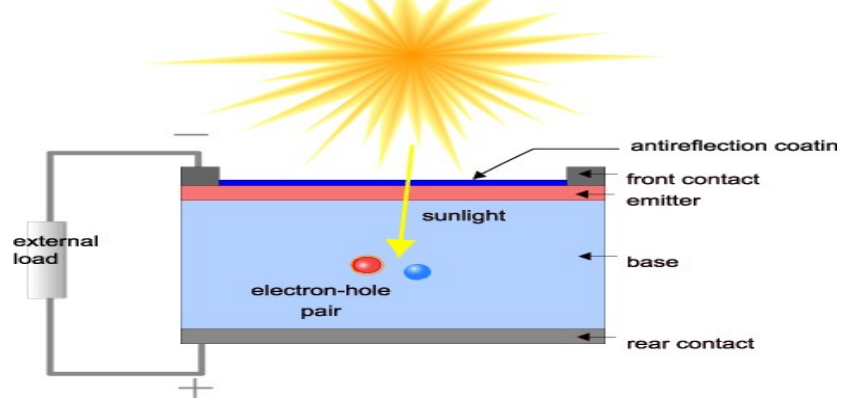

Fig1.Basic solar energy conversion system

A solar cell is an electronic device which directly converts sunlight into electricity. Light shining on the solar cell produces both a current and a voltage to generate electric power. This process requires firstly, a material in which the absorption of light raises an electron to a higher energy state, and secondly, the movement of this higher energy electron from the solar cell into an external circuit. The electron then dissipates its energy in the external circuit and returns to the solar cell. A variety of materials and processes can potentially satisfy the requirements for photovoltaic energy conversion, but in practice nearly all photovoltaic energy conversion uses semiconductor materials in the form of a $p$ - $n$ junction. 
Mathematical modelling of PV module is being continuously updated to enable researcher to have a better understanding of its working [1-6].In this paper, a step-by-step procedure for simulating PV module with simple subsystem blocks, with user-friendly icons and dialog in the same way as Matlab/ Simulink block libraries is developed. The step-by-step modelling procedure of PV module as well as DC/DC converter, PWM inverter through connected to Grid is presented with simulation results for different conditions of irradiation.

Photovoltaic systems require interfacing power converters between the PV arrays and the grid. These power converters are used for two major tasks. First, to ensure that the PV arrays are operated at the maximum power point (MPPT) [2-7]. Second, to inject a sinusoidal current into the grid. Normally there are two power converters [8]. The first one is a DC/DC power converter. that is used to operate the PV arrays at the maximum power point. The other one is a DC/AC power converter to interconnect the photovoltaic system to the grid. The classical single or three-phase two level voltage source inverter is normally used for this power converter type [9-12]. However, other topologies have been proposed. Multilevel converter topologies are a very interesting choice for realizing this objective.

There are several PV system configurations. These configurations are the centralized technology, string technology, multi-string technology and AC-module technology. The number and type of power converters that is used to interconnect the PV system to the grid is dependent of the technology that is used. The multi-string technology has several different groups of PV arrays. Each group is connected in series with a DC/DC converter. This allows using this technology with some multilevel topologies, such as, the cascaded multicell inverters. This topology is based on the series connection of single-phase inverters with separated DC sources. In this way, each group of PV arrays will be used as a single DC source. This allows avoiding high voltage amplification. In order to obtain a galvanic connection between the grid and the PV generator many PV systems use a power transformer, avoiding that a leakage current may flow through the capacitance between PV generator and ground. Some systems use a transformer embedded in a high-frequency DC/DC converter. Others use a line frequency transformer at the output of the inverter.

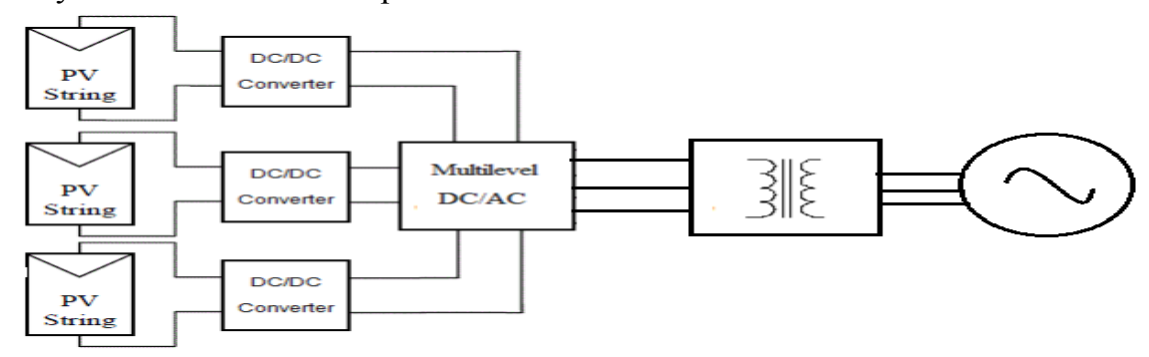

Fig.2 PV modules connected to grid via Multilevel inverter

This mechanism proposes a three -phase multistring five-level inverter topology. It consists of three strings of PV arrays connected to their own dc-dc boost converter. An auxiliary circuit comprising four diodes and a switch is configured together with a conventional full-bridge inverter to form this topology. A SPWM control scheme is introduced to generate switching signals for the switches and to produce five output-voltage levels: zero, $+1 / 2 \mathrm{Vdc}, \mathrm{Vdc},-1 / 2 \mathrm{Vdc}$, and $-\mathrm{Vdc}$ (assuming that $\mathrm{Vdc}$ is the supply voltage). This inverter topology uses two reference signals instead of one to generate PWM signals for the switches. Both reference signals Vref1 and Vref2 are identical to each other, except for an offset value that is equivalent to the amplitude of carrier signal Vcarrier. Because the inverter is used in a PV system, a proportional-integral (PI) current control scheme is employed to keep the output current sinusoidal and to have high dynamic performance under rapidly changing atmospheric conditions and to maintain the power factor at near unity. Simulation and experimental results are presented to validate the proposed inverter configuration.

\section{Mathematical Model For Pv Module}

A solar cell is basically a p-n junction fabricated in a thin wafer of semiconductor. The electromagnetic radiation of solar energy can be directly converted to electricity through Photovoltaic effect. Being exposed to the sunlight, photons with energy greater then the band-gap energy of the semiconductor creates some electronhole pairs proportional to the incident irradiation.

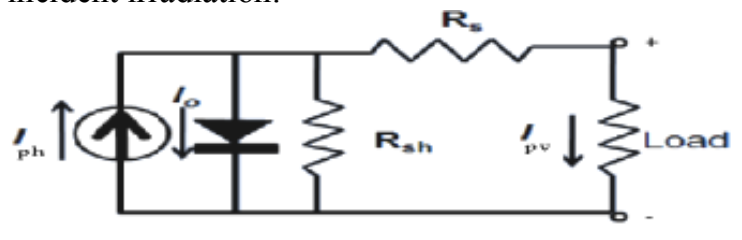

Fig.3: Equivalent diagram of PV cell 
A model of PV module with moderate complexity that includes the temperature independence of the photocurrent source, the saturation current of the diode, and a series

Resistance is considered based on the Shockley diode equation.

The current source Iph represents the cell photocurrent. Rsh and Rs are the intrinsic shunt and series resistances of the cell, respectively. Usually the value of Rsh is very large and that of Rs is very small, hence they may be neglected to simplify the analysis. PV cells are grouped in larger units called PV modules which are further interconnected in a parallel-series configuration to form PV arrays.

The photovoltaic panel can be modelled mathematically as given in equations (1)- (4) [3] - [5]. Module photocurrent:

$$
I_{p h}=\left[I_{S C r}+K_{i}(T-298)\right] * \frac{\lambda}{1000}
$$

Modules reverse saturation current - Irs:

$$
I_{r s}=\left[I_{S C r}\right] /\left[\exp \left(\frac{q V_{O C}}{N_{S} k A T}\right)-1\right]
$$

The module saturation current IO varies with the cell temperature, which is given by

$$
I_{O}=\left[I_{r s}\right]\left[\frac{T}{T_{r}}\right] *\left[\exp \left(\frac{q * V_{g o}}{B k}\left\{\frac{1}{T_{r}}-\frac{1}{T}\right\}\right)-1\right]
$$

The current output of PV module is

$$
I_{P V}=N_{P} * I_{p h}-N_{P} * I_{o}\left[\exp \left(\frac{q *\left(V_{P V}+I_{P V} R_{S}\right.}{N_{S} A k T}\right)-1\right]
$$

Where $\mathrm{Vpv}=\mathrm{Voc}, \mathrm{Np}=1$ and $\mathrm{Ns}=36$

PV module represents the fundamental power conversion unit of a PV generator system. The output characteristics of a PV module depend on the solar insolation, the cell temperature and the output voltage of the PV module. Since PV module has nonlinear characteristics, it is necessary to model it for the design and simulation of maximum power point tracking (MPPT) for PV system applications.

The above mentioned equations are modelled by using common Simulink blocks as shown below fig:3

a. Subsystem 1 is shown in Figure 4. This model converts the module operating temperature given in degrees Celsius to Kelvin.

b. subsystem 2 This model calculates the short circuit current (ISC) at given operating temperature. Figure 4 gives the circuit under subsystem.

c. Subsystem 3 is shown in Figure 4. This model takes short circuit current ISC at reference temp. $=2.55 \mathrm{~A}$ and Module reference temperature $\operatorname{TrK}=25 \mathrm{oC}$ as input.

d. Subsystem 4 This model takes reverse saturation current Irs, Module reference temperature $\operatorname{TrK}=250 \mathrm{C}$ and Module operating temperature $\mathrm{TaK}$ as input and calculates module saturation current.

e. This model takes operating temperature in Kelvin TaK and calculates the product NsAkT, the denominator of the exponential function in equation (4).

f. This model executes the function given by the equation (4). The following function equation is used. This gives the circuit under subsystem 6 .

$$
\operatorname{IPV}=u(3)-u(4) *(\exp ((\mathrm{u}(2) *(\mathrm{u}(1)+\mathrm{u}(6))) /(\mathrm{u}(5)))-1)
$$

All the above six subsystem models are interconnected in such a way that to produce PV current at corresponding voltage.

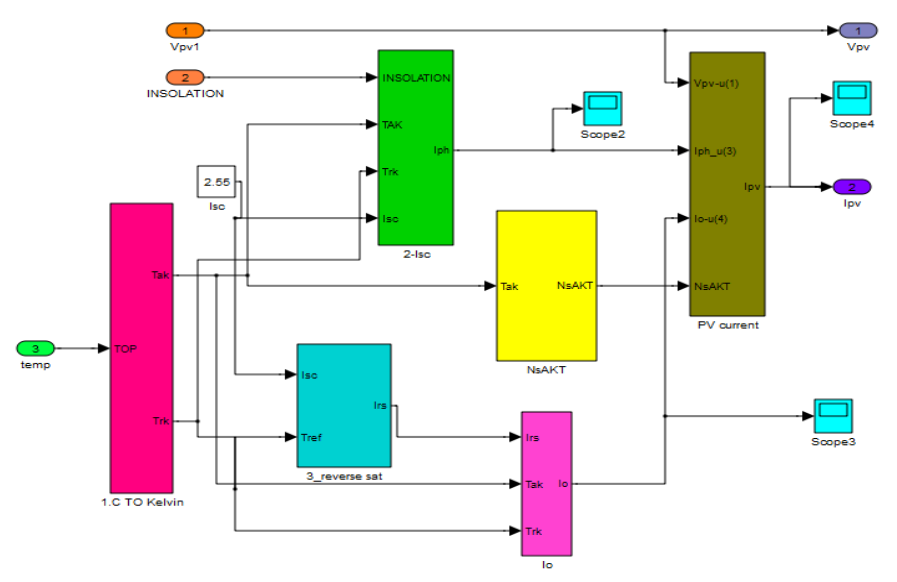

Fig.4 Interconnected Simulink model for all equations sub systems 
The final model takes irradiation; operating temperature in Celsius and module voltage as input and gives the output current Ipv and output voltage Vpv and Rated Power Ppv.The workspace is added to measure Ipv, Vpv, and Ppv in this model.

\section{Modelling Of Multistring Five-Level Inverter Topology}

The proposed Three-phase multistring five-level inverter topology is shown in Fig. 5. It consists of three dc-dc boost converters connected to a common dc bus, an auxiliary circuit, and a full-bridge inverter configuration. Input sources, PV string 1, PV string 2, and PV string 3 are connected to the inverter via the dc$\mathrm{dc}$ boost converters. Because the proposed inverter is used in a grid-connected PV system, the utility grid is used instead of a load. The dc-dc boost converters are used to track the maximum power point (MPP) independently and to step up inverter output voltage $V$ inv to be more than $\sqrt{ } 2$ of grid voltage $V g$ to ensure power flow from the PV arrays into the grid [12].

$$
V_{i n}>\sqrt{2} \frac{V_{g}}{2 V_{i n}}
$$

The dc-dc boost converters are connected in parallel to avoid high dc-bus voltage, which will eventually increase the size of the capacitors and the inverter's cost. Therefore, only two capacitors with equal capacitance rating are used as the dc bus, and the other dc-dc boost converters are connected to this dc bus, as shown in Fig. 5 .

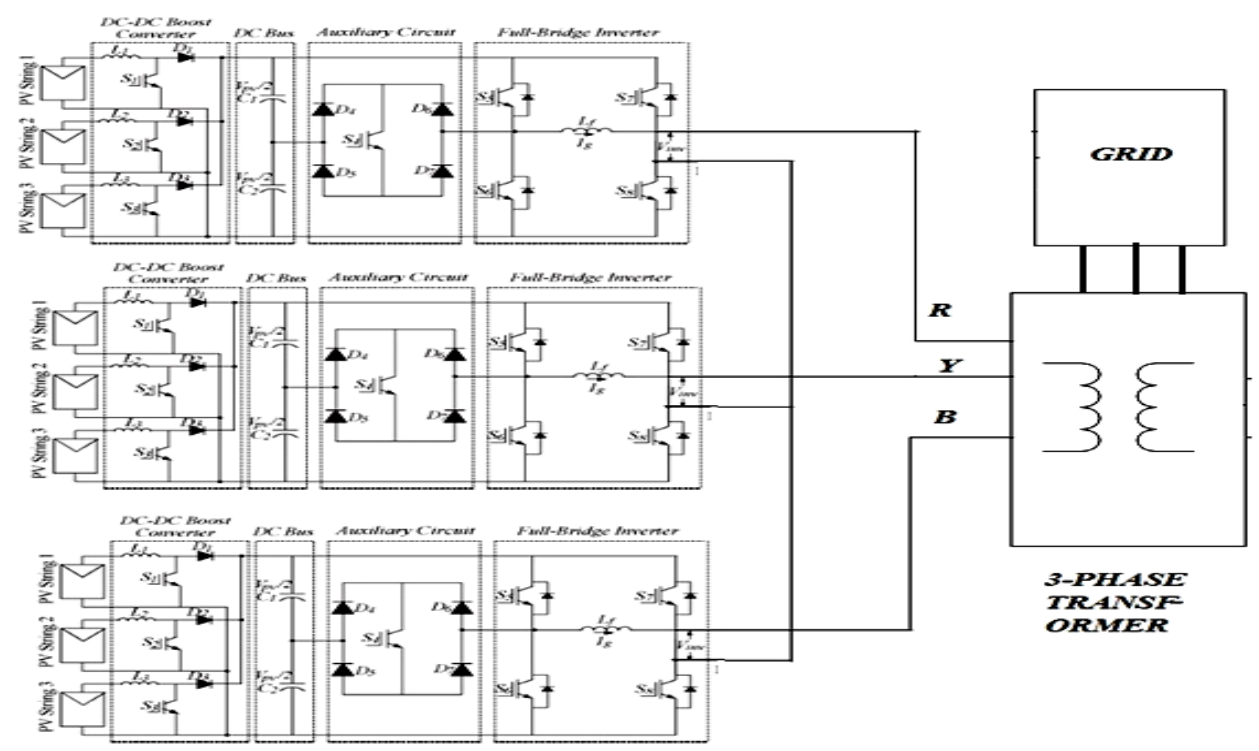

Fig.5: Proposed approach of multilevel inverter

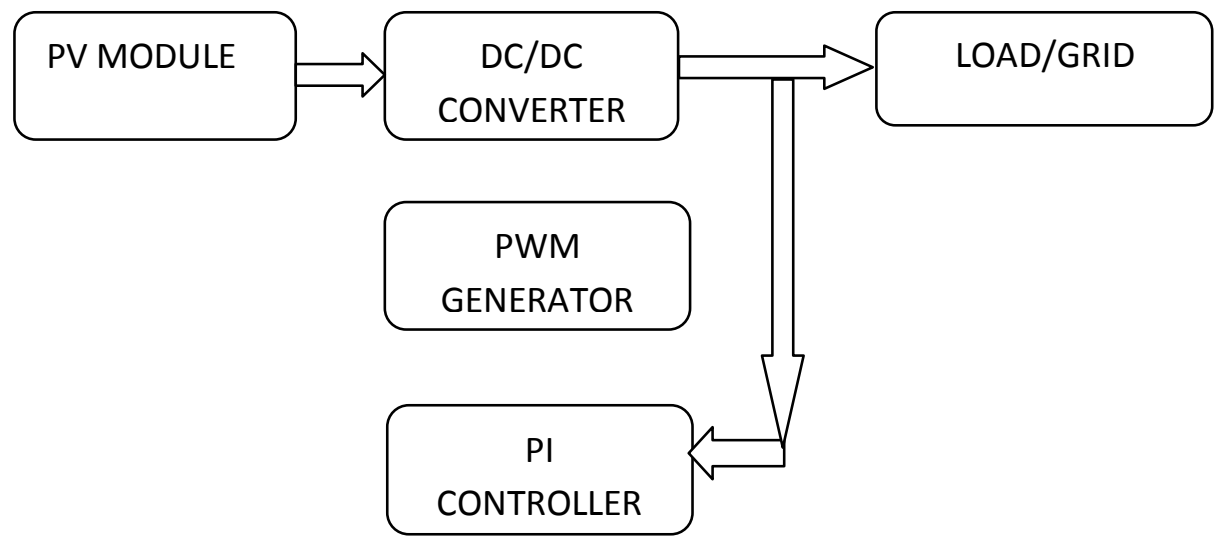

Fig.6: Equivalent model of Pv module connected to grid

A filtering inductance $L f$ is used to filter the current injected into the grid. The injected current must be sinusoidal with low harmonic distortion. In order to generate sinusoidal current, a sinusoidal PWM is used because it is one of the most effective methods. A sinusoidal PWM is obtained by comparing a high frequency carrier signal with a low-frequency sinusoid signal, which is the modulating or reference signal. The carrier has 
a constant period; therefore, the switches have constant switching frequency. The switching instant is determined from the crossing of the carrier and the modulating signal.

Modulation index $M a$ for a five-level PWM inverter is given as [13-14]

$$
M_{a}=\frac{A_{m}}{2 A_{c}}
$$

where $A c$ is the peak-to-peak value of carrier and $A m$ is the peak value of voltage reference Vref. Because, in this paper, two reference signals that are identical to each other are used, (vii) can be expressed in terms of the amplitude of carrier signal $V c$ by replacing $A c$ with $V c$, and $A m=V$ refl $=V$ ref2 $=V$ ref

$$
M=\frac{V_{r e f}}{2 v_{c}}
$$

From the PWM modulation, the analysis of harmonic components in the proposed inverter can be preformed. The output voltage produced by comparison of the two reference signals and the carrier signal can be expressed as [7]

$$
V_{0}(\theta)=A_{0}+\sum_{n=1}^{\infty}\left(A_{n} \cos n \theta+B_{n} \sin n \theta\right)
$$

If there are $P$ pulses per quarter period, and it is an odd number, coefficients $B n$ and $A o$ would be zero, where $n$ is an even number. Therefore, the (ix) can be rewritten as

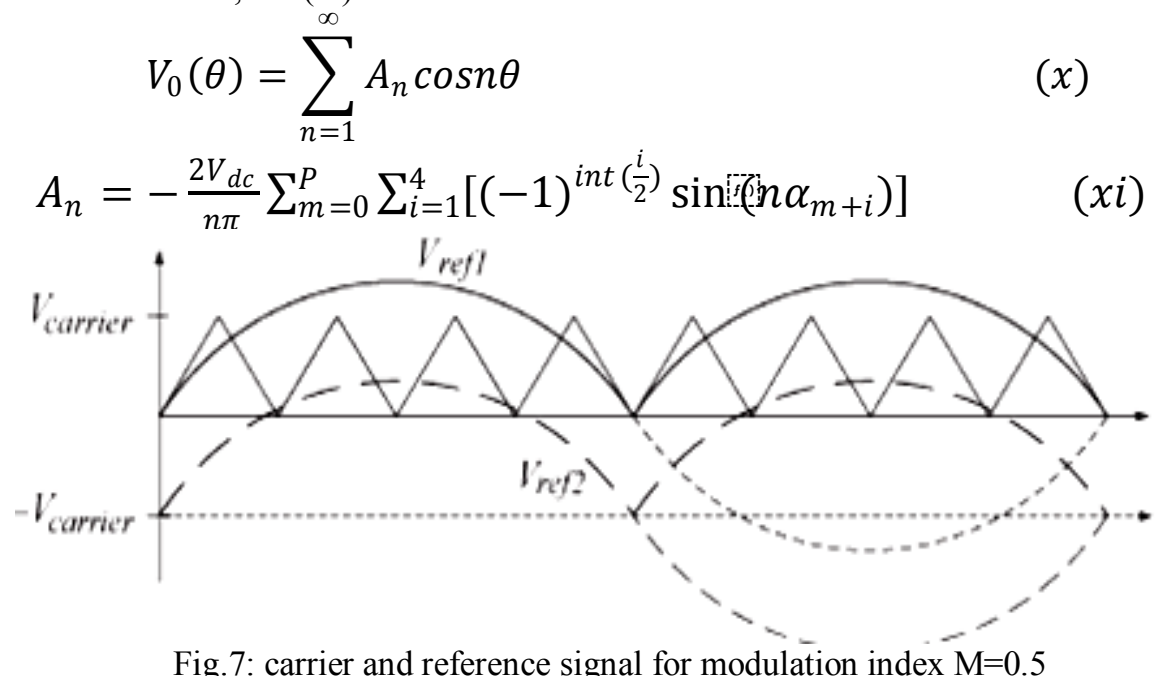

Fig.7: carrier and reference signal for modulation index $\mathrm{M}=0.5$

where $\mathrm{m}$ is a pulse number and $\alpha$ is the phase displacement angle. The Fourier series coefficients of the conventional single phase full-bridge inverter by sinusoidal PWM is given as

$$
A_{n}=-\frac{V_{d c}}{n \pi} \sum_{m=1}^{p}\left[(-1)^{m} \sin \left(\ln \alpha_{m}\right)\right]
$$

Combinations of PV strings are used as the input voltage sources. The voltage across the strings are known as $V \mathrm{pv} 1, V \mathrm{vp} 2$, and $V \mathrm{pv} 3$. Referring to (1) and (2), $V \mathrm{pv} 1, V \mathrm{vp} 2$, and $V \mathrm{vp} 3$ are boosted by the dc-dc boost converters to exceed grid voltage $V g$, and the voltage across the dc bus is known as $V \mathrm{pv}$. The operating principle of the proposed inverter is to generate five output-voltage levels, i.e., $0,+V \mathrm{pv} / 2,+V \mathrm{pv},-V \mathrm{pv} / 2,-V \mathrm{pv}$, as in Fig. 8. As shown in Fig. 5, an auxiliary circuit that consists of four diodes and a switch $S 4$ is used between the dcbus capacitors and the full-bridge inverter. Proper switching control of the auxiliary circuit can generate half level of PV supply voltage, i.e., $+\mathrm{Vpv} / 2$ and -Vpv/2 [15-17]. 


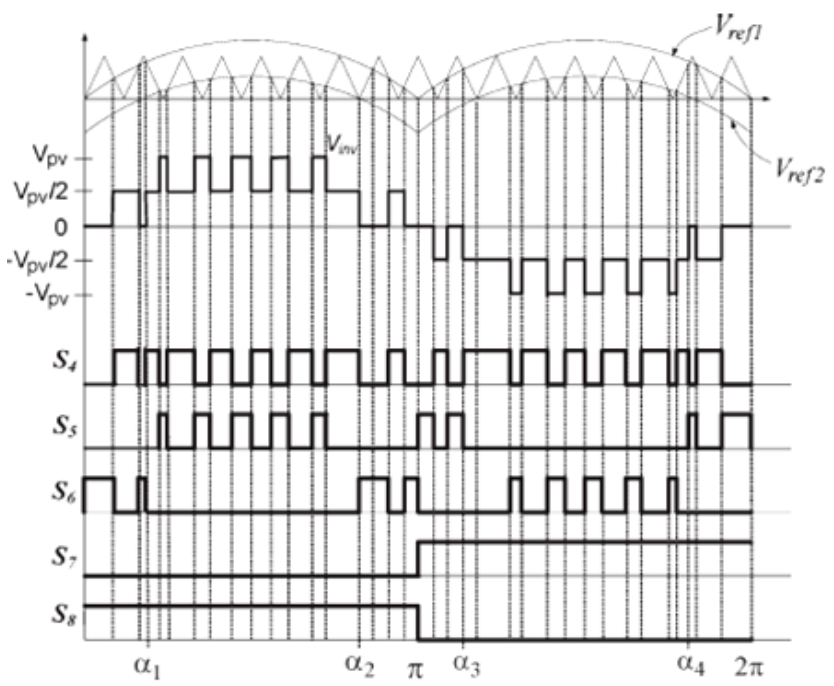

Fig. 8. Inverter output voltage $(V$ inv $)$ and switching pattern for the five-level inverter

Two reference signals Vref1 and Vref2 will take turns to be compared with the carrier signal at a time. If Vref1 exceeds the peak amplitude of carrier signal Vcarrier, then Vref2 will be compared with the carrier signal until it reaches zero. At this point onward, Vrefl takes over the comparison process until it exceeds Vcarrier. This will lead to a switching pattern, as shown in Fig. 8. Switches S4-S6 will be switching at the rate of the carrier signal frequency, while S7 and S8 will operate at a frequency that is equivalent to the fundamental frequency. Table I illustrates the level of Vinv during S4-S8 switch on and off. If one of the PV strings is disconnected from the dc bus, the operation of the other $\mathrm{dc}-\mathrm{dc}$ boost converters will not be affected because they are connected in parallel. As the dc-dc boost converters are used to track the MPPT point, it can be concluded that the MPPT of the PV strings is done independently. Later expansion of the PV strings is also possible by adding a dc-dc boost converter, as shown in Fig. 5.

TABLE I

Inverter Output Voltage during S4-S8 switch ON and OFF

\begin{tabular}{|l|l|l|l|l|l|}
\hline S4 & S5 & S6 & S7 & S8 & Vinv \\
\hline 1 & 0 & 0 & 0 & 1 & + Vpv12 \\
\hline 0 & 1 & 0 & 0 & 1 & + Vpv \\
\hline & 1 & 0 & 1 & 0 & 0 \\
\hline 1 & 0 & 1 & 0 & 1 & - Vpv12 \\
\hline 0 & 0 & 0 & 1 & 0 & $-V p v$ \\
\hline
\end{tabular}

(a) PV Module

IV. Simulation Results And Discussion

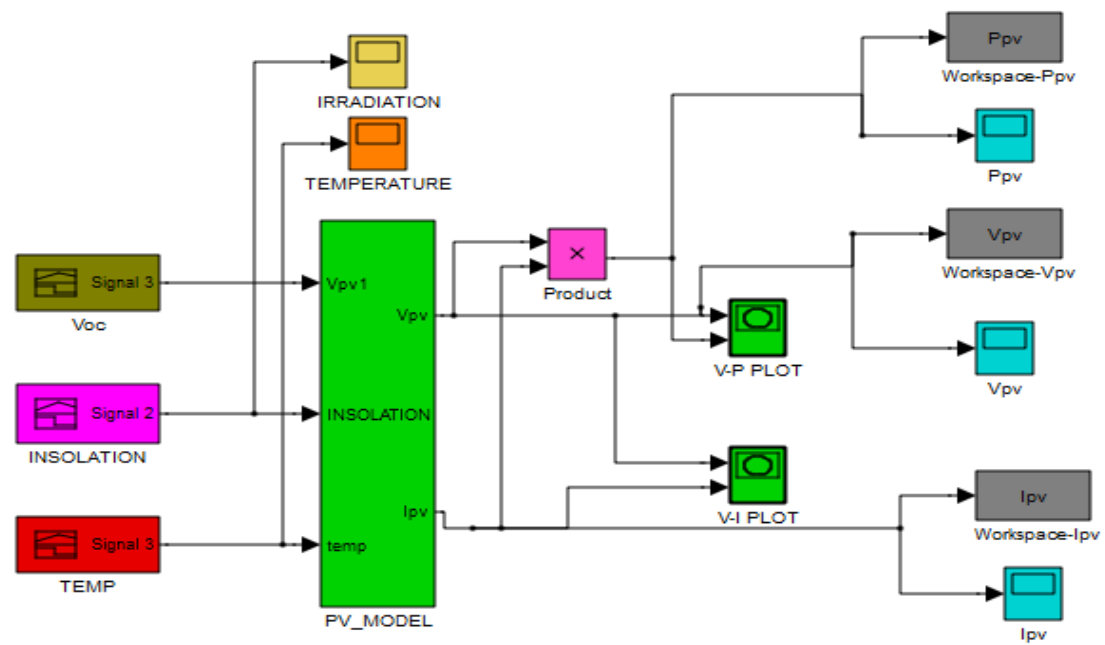

Fig.9: Simulink model of PV module with workspace 
With the developed model, the PV module characteristic is estimated as follows.

(1) I-V and P-V characteristics under varying irradiation with constant temperature are obtained as shown in Figures 9 (a) to 9 (d). Between 0 and $1 \mathrm{~s}$, the irradiation is $200 \mathrm{~W} / \mathrm{m} 2$, between 1 and $2 \mathrm{~s}$ it is $600 \mathrm{~W} / \mathrm{m}$, while from $2 \mathrm{~s}$ onwards it is $1000 \mathrm{~W} / \mathrm{m} 2$.

2. In Figure 9(b), the input temperature is shown which is constant at $25_{O C}$.

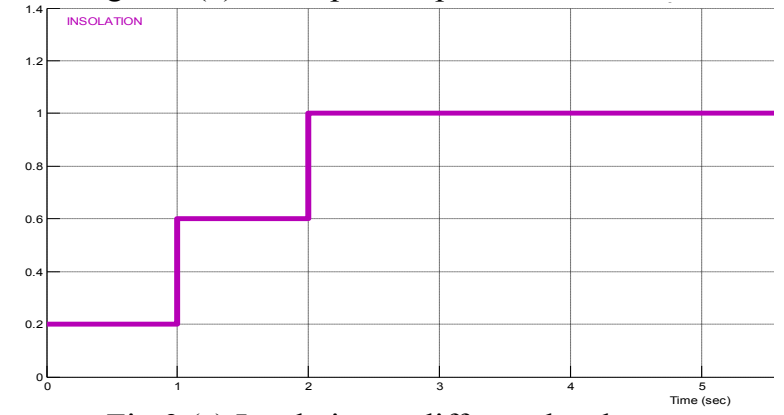

Fig.9 (a) Insolation at different levels

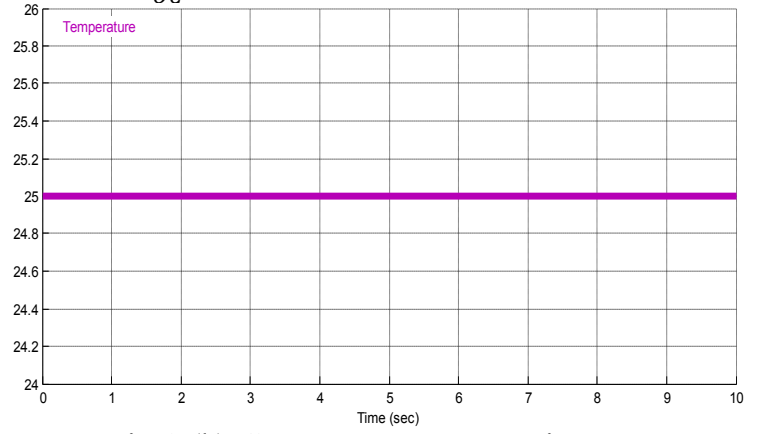

Fig.9 (b) Constant temperature input

3. The I-V and P-V output characteristics of PV module with varying irradiation at constant temperature are shown in Figure 9(c) and 9(d).

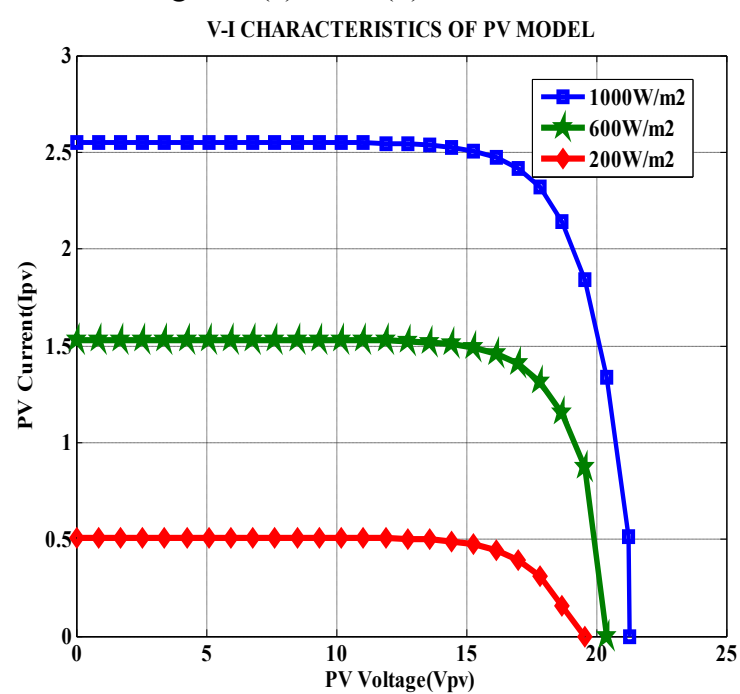

Fig 9(c). Output - I-V characteristics with varying irradiation

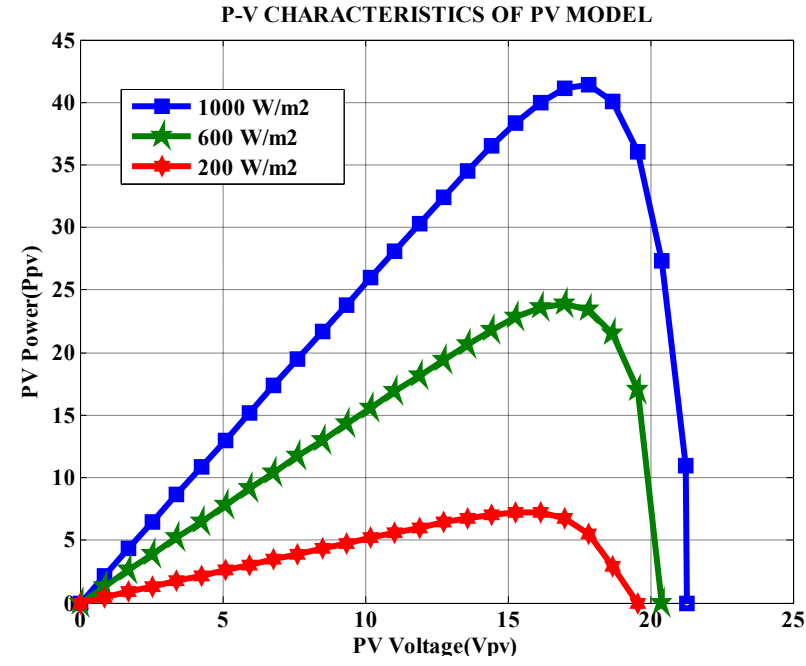

Fig 9(d). Output - P-V characteristics with varying irradiation

From the above plots we can conclude that, when the irradiation increases,

A. The current output increases

B.The voltage output also increases. This results in net increase in power output with increase in irradiation at constant temperature.

II. I-V and P-V Characteristics under constant irradiation with varying temperature are obtained in Figures 10(a) to $10(\mathrm{~d})$.

1. In Figure 10(a) the time varying temperature signal is shown. Between 0 and 1 second, the temperature of 25 $\mathrm{C}$ is applied and it is increased to 50 and $750 \mathrm{C}$.

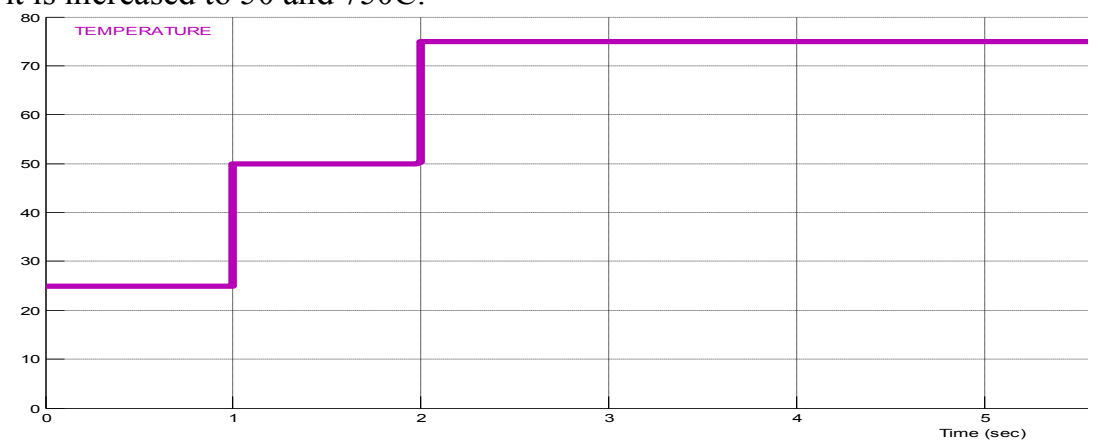

Fig 5(a). Input - Time varying temperature 
2. The I-V output characteristics of PV module with varying temperature at constant irradiation of $1000 \mathrm{~W} / \mathrm{m} 2$ are shown in Figure 10(b).

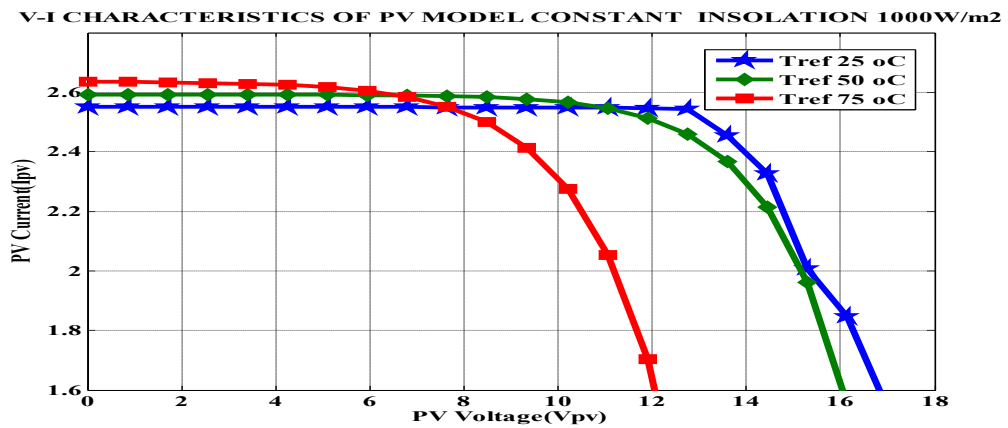

Figure 10(b). Output - I-V characteristics with varying temperature

3. The P-V output characteristics of PV module with varying temperature at constant irradiation are shown in Figure 10(c).

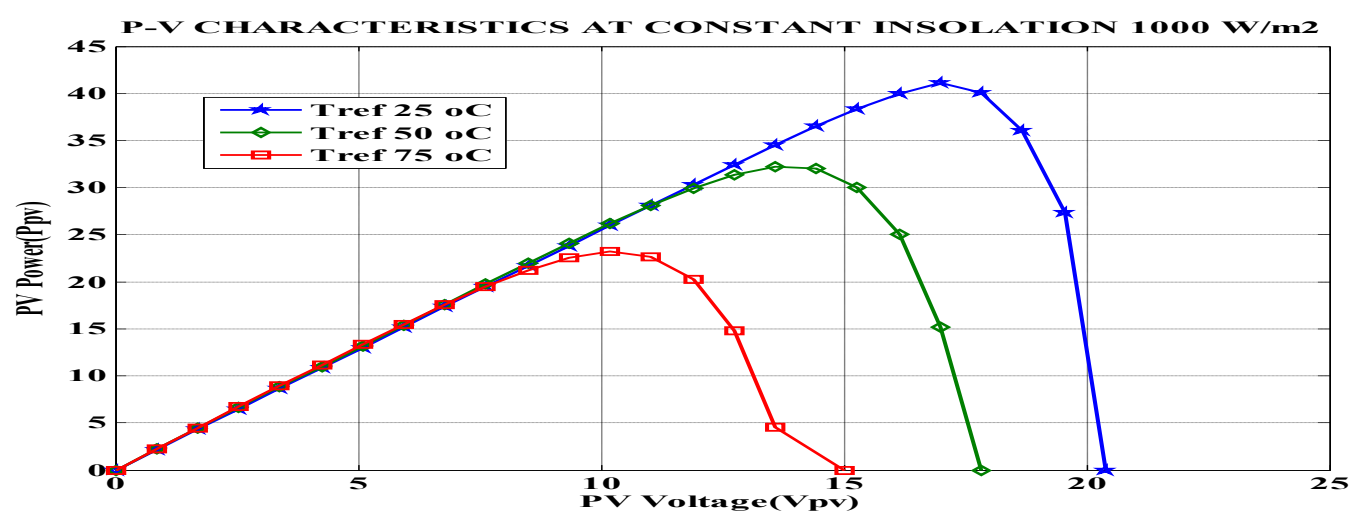

Figure 10(c). Output - P-V characteristics with varying temperature

From above Case-ii we can conclude that, when the operating temperature increases,

A. The current output increases marginally, but the voltage output decreases drastically

B.Results in net reduction in power output with rise in temperature

The results are verified and found matching with the manufacturer's data sheet output curves.

\section{(b) GRID Connected system}

Simulations were performed by using MATLAB/Simulink to verify that the proposed inverter can practically be implemented in a PV system. It helps one to confirm the PWM switching strategy for the multistring five-level inverter. Then, this strategy is implemented in a real-time environment, i.e., the DSP to produce PWM switching signals for the switches. Fig. 10(a) shows the way the PWM switching signals are generated by using two reference signals and a triangular carrier signal. The resulting PWM signals for switches S4-S8 are shown in Fig. 10(b)-(f). Note that one leg of the inverter is operating at a high switching rate that is equivalent to the frequency of the carrier signal, while the other leg is operating at the rate of fundamental frequency (i.e., $50 \mathrm{~Hz}$ ). The switch at the auxiliary circuit (S4) also operates at the rate of the carrier signal. As mentioned earlier, modulation index $M$ will determine the shape of inverter output voltage $V$ inv and grid current $I g$. Fig. 11 shows the simulation results of $V \mathrm{inv}$ and $I g$ for different values of $M$. The dc-bus voltage is set to 200 $\mathrm{V}$.

Below figures shows that the power generated from Photo voltaic modules are collected as a DC source of low voltage, thus generated voltage was step up by using DC-DC converters as a $200 \mathrm{~V}$. The voltage produced by converter is not AC source, to convert DC to Alternating current we used here a Inverter consisting of Sinusoidal Pulse width Modulation. The Harmonics generated by the source is very less and power factor is almost near by unity. 


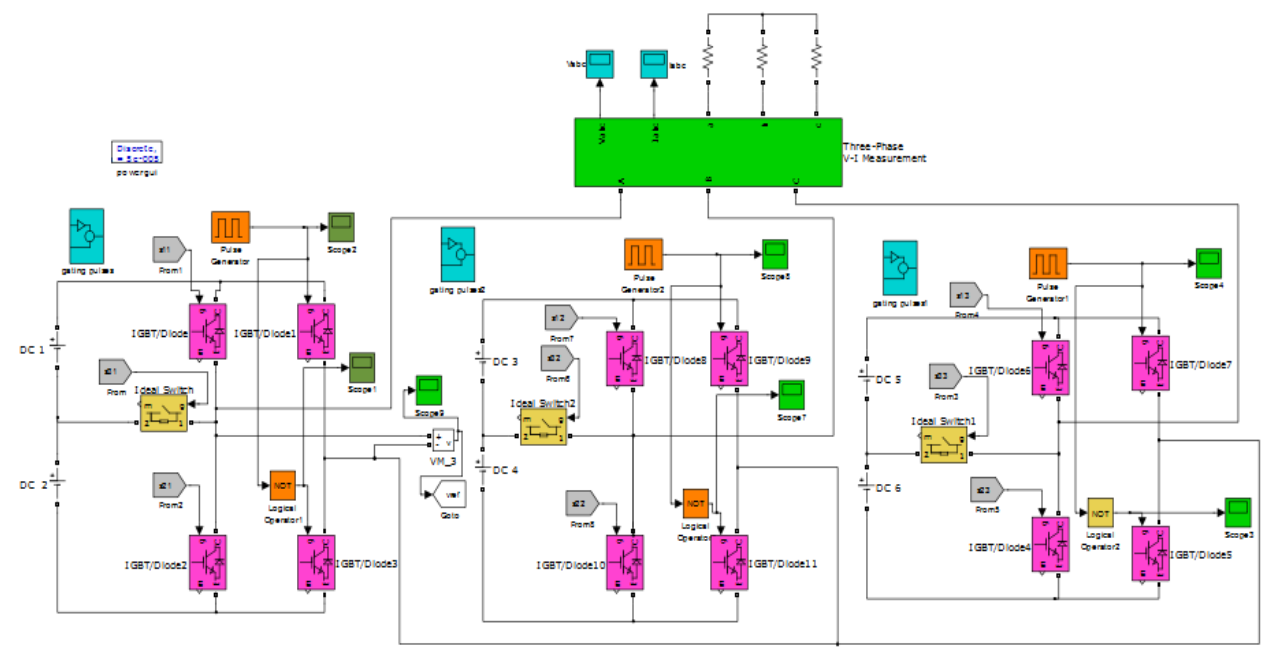

Fig.11: Multilevel inverter for three phase system

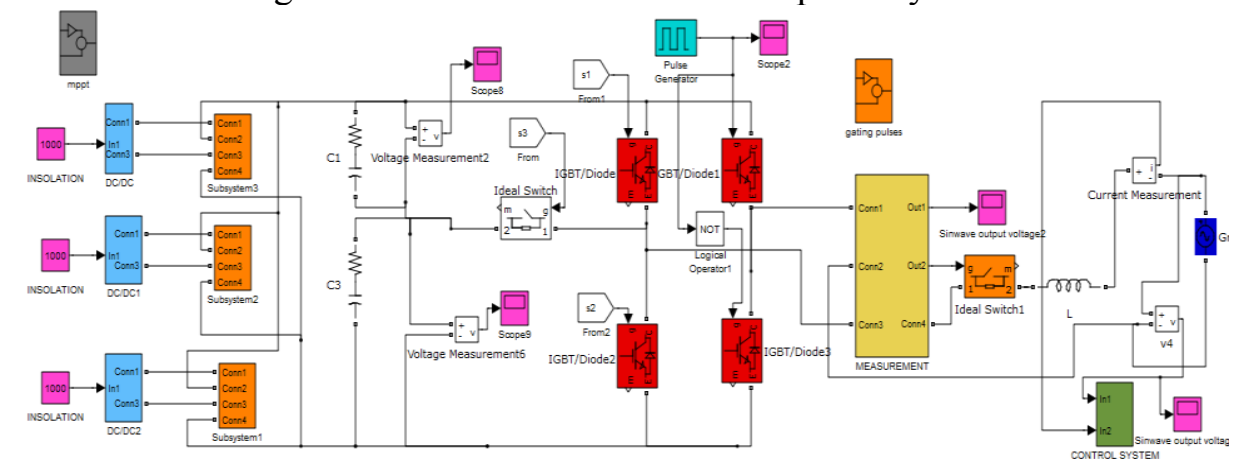

Fig.12: Simulink block with PV and control strategy of Grid system

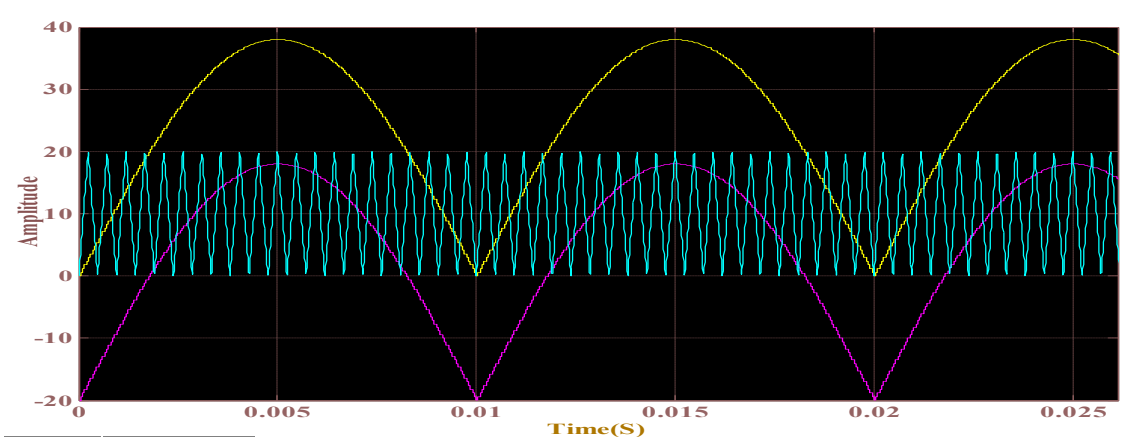

Fig.12(a).Reference and carrier signal generation

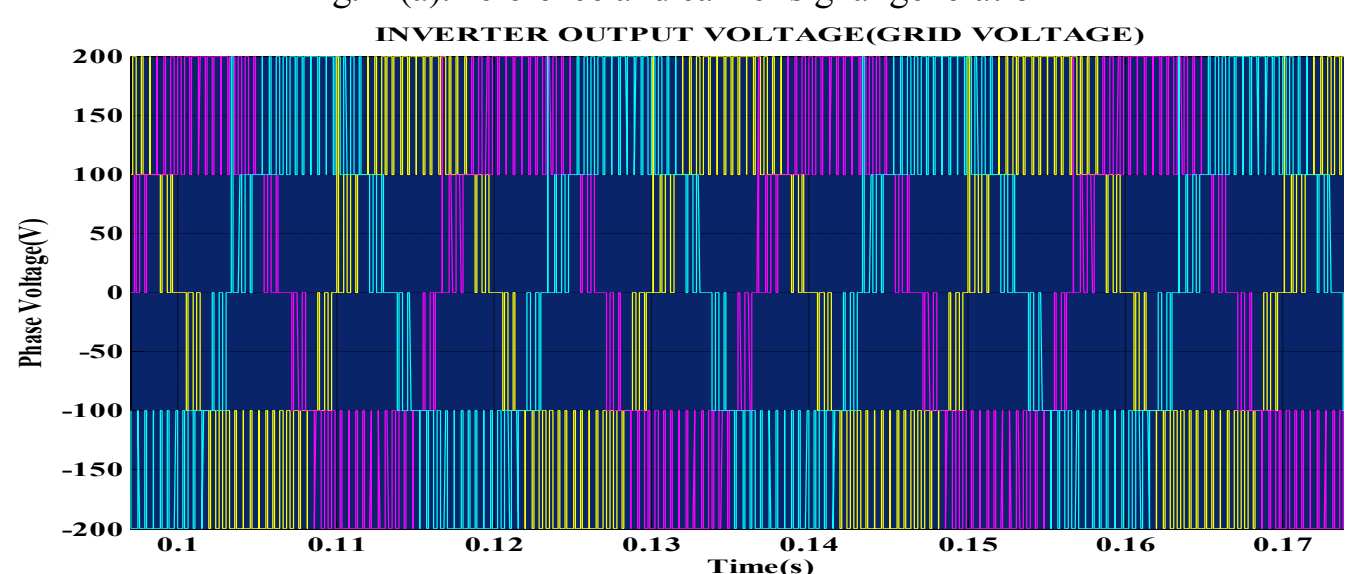

Fig.12 (b).Inverter output voltage i.e. grid connected voltage 


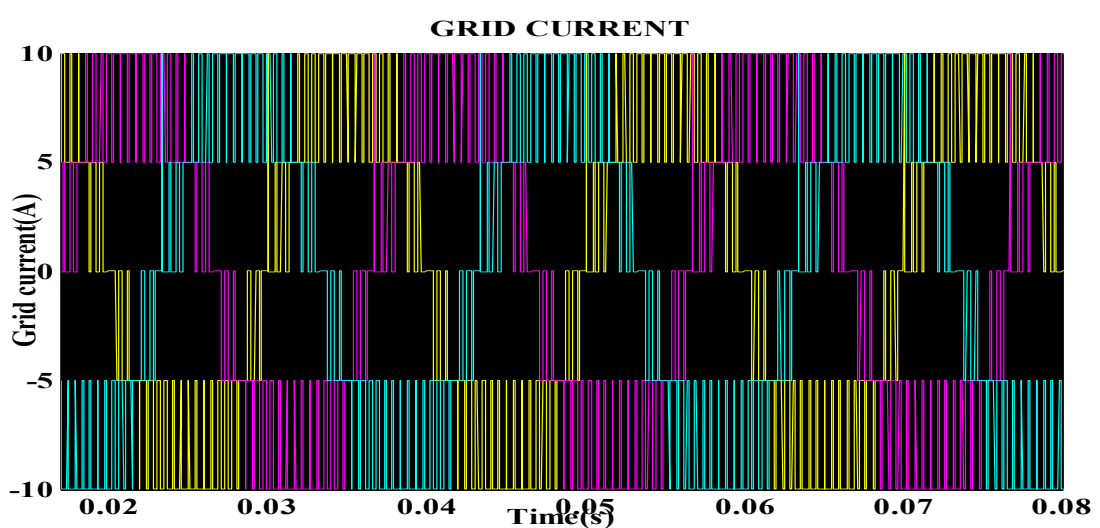

Fig.12(c).Inverter output current i.e. grid current

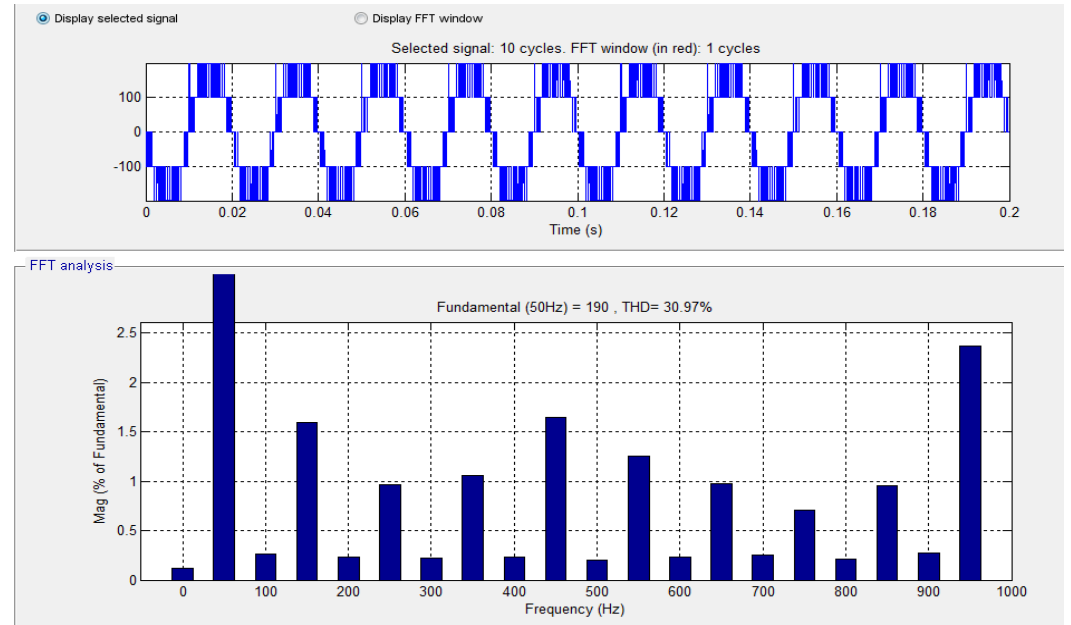

Fig.12(d).FFT analysis of grid connected system_R_Phase

\section{Conclusion}

This paper has presented the step-by-step procedure for modelling the PV module is presented with three-phase multistring five-level inverter for PV application. This mathematical modelling procedure serves as an aid to induce more people into photovoltaic research and gain a closer understanding of I-V and P-V characteristics of PV module. A novel PWM control scheme with two reference signals and a carrier signal has been used to generate the PWM switching signals. The circuit topology, control algorithm, and operating principle of the proposed inverter have been analysed in detail. The configuration is suitable for PV application as the PV strings operate independently and later expansion is possible. Furthermore, the experimental results indicate that the THD of the multistring five-level inverter is much less than that of the conventional multistring three-level inverter. In addition, both grid voltage and grid current are in phase at near-unity power factor.

\section{Proceedings Papers:}

\section{References}

[1 ] M.Veerachary, "Power Tracking for Nonlinear PV Sources with Coupled Inductor SEPIC Converter," IEEE Transactions on Aerospace and Electronic Systems, vol. 41, No. 3, July 2005

[2] I. H. Altas and A.M. Sharaf, "A Photovoltaic Array Simulation Model for Matlab-Simulink GUI Environment," IEEE, Clean Electrical Power, International Conference on Clean Electrical Power (ICCEP '07), June 14-16, 2007, Ischia, Italy.

[3] S.Chowdhury, S.P.Chowdhury, G.A.Taylor, and Y.H.Song, "Mathematical Modelling and Performance Evaluation of a StandAlone Polycrystalline PV Plant with MPPT Facility," IEEE Power and Energy Society General Meeting - Conversion and Delivery of Electrical Energy in the 21st Century, July 20-24, 2008, Pittsburg, USA.

[4] Jee-Hoon Jung, and S. Ahmed, "Model Construction of Single Crystalline Photovoltaic Panels for Real-time Simulation," IEEE Energy Conversion Congress \& Expo, September 12-16, 2010, Atlanta, USA.

[5] S. Nema, R.K.Nema, and G.Agnihotri, "Matlab / Simulink based study of photovoltaic cells / modules / array and their experimental verification," International Journal of Energy and Environment, pp.487- 500, Volume 1, Issue 3, 2010.

[6] N. A. Rahim and S. Mekhilef, "Implementation of three-phase grid connected inverter for photovoltaic solar power generation system," in Proc. IEEE PowerCon, Oct. 2002, vol. 1, pp. 570-573. 


\section{Journal Papers:}

[7] Aryuanto Soetedjo*, Abraham Lomi, Yusuf Ismail Nakhoda, Awan Uji Krismanto, “Modelling of Maximum Power Point Tracking Controller for Solar Power System: TELKOMNIKA, , pp. 419 430 e-ISSN: 2087-278X., Vol.10, No.3, July 2012.

[8] V. Fernão Pires*, J. F. Martins**, D. Foito*, Chen Hão, “ A Grid Connected Photovoltaic System with a Multilevel Inverter and a Le-Blanc Transformer," INTERNATIONAL JOURNAL of RENEWABLE ENERGY RESEARCH Vitor Fernão Pires et al., Vol.2, No.1, 2012.

[9] Alias Khamis, Mohamed,H. Shareef,A. Ayob” Modelling and simulation of a micro grid tested using photovoltaic and battery based power generation" Journal of Asian Scientific Research 2(11):658-666

[10] Tarak Salmi*, Mounir Bouzguenda**, Adel Gastli**, Ahmed Masmoudi* "MATLAB/Simulink Based Modelling of Solar Photovoltaic Cell," INTERNATIONAL JOURNAL of RENEWABLE ENERGY RESEARCH Tarak Salmi et al., Vol.2, No.2, 2012.

[11] M. Meinhardt and G. Cramer, "Past, present and future of grid-connected photovoltaic- and hybrid-power-systems," in Proc. IEEEPES Summer Meeting, Jul. 2000, vol. 2, pp. 1283-1288.

\section{Proceedings Papers:}

[12] S. Kouro, J. Rebolledo, and J. Rodriguez, "Reduced switching-frequency modulation algorithm for high-power multilevel inverters," IEEE Trans. Ind. Electron., vol. 54, no. 5, pp. 2894-2901, Oct. 2007.

[13] S. J. Park, F. S. Kang, M. H. Lee, and C. U. Kim, “A new single-phase five level PWM inverter employing a deadbeat control scheme," IEEE Trans. Power Electron., vol. 18, no. 18, pp. 831-843, May 2003.

[14] L. M. Tolbert and T. G. Habetler, "Novel multilevel inverter carrier-based PWM method," IEEE Trans. Ind. Appl., vol. 35, no. 5, pp. 1098-1107, Sep./Oct. 1999.

[15] Y. Liu, H. Hong, and A. Q. Huang, "Real-time calculation of switching angles minimizing THD for multilevel inverters with step modulation," IEEE Trans. Ind. Electron., vol. 56, no. 2, pp. 285-293, Feb. 2009.

[16] N. S. Choi, J. G. Cho, and G. H. Cho, "A general circuit topology of multilevel inverter," in Proc. IEEE 22th Annu. PESC, Jun. 2427, 1991, pp. 96-103.

[17] G. Carrara, S. Gardella, M. Marchesoni, R. Salutari, and G. Sciutto, "A new multilevel PWM method: A theoretical analysis," IEEE Trans. Power Electron., vol. 7, no. 3, pp. 497-505, Jul. 1992.

Vpv is output voltage of a PV module (V)

\section{NOMENCLATURE}

Ipv is output current of a PV module (A)

$\operatorname{Tr}$ is the reference temperature $=298 \mathrm{~K}$

$\mathrm{T}$ is the module operating temperature in Kelvin

Iph is the light generated current in a PV module (A)

Io is the PV module saturation current (A)

$\mathrm{A}=\mathrm{B}$ is an ideality factor $=1.6$

$\mathrm{k}$ is Boltz man constant $=1.3805 \times 10-23 \mathrm{~J} / \mathrm{K}$

$\mathrm{q}$ is Electron charge $=1.6 \times 10-19 \mathrm{C}$

Rs is the series resistance of a PV module

ISCr is the PV module short-circuit current at $25 \mathrm{oC}$ at $1000 \mathrm{~W} / \mathrm{m} 2=2.55 \mathrm{~A}$

$\mathrm{Ki}$ is the short-circuit current temperature co-efficient at ISCr $=0.0017 \mathrm{~A} / \mathrm{oC}$

$\lambda$ is the $\mathrm{PV}$ module illumination $(\mathrm{W} / \mathrm{m} 2)=1000 \mathrm{~W} / \mathrm{m} 2$

Ego is the band gap for silicon $=1.1 \mathrm{eV}$

Ns is the number of cells connected in series

Ma is Modulation index

Vout Inverter output voltage

$\mathrm{Vg}$ is Grid voltage,Ig is Grid current

$\mathrm{Np}$ is the number of cells connected in parallel.

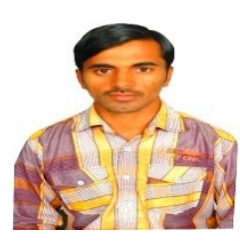

Lunavath. Hemsingh was born in Andhra Pradesh, India, in 1988. He received the B.Tech (EEE) degree from Jawaharlal Nehru Technological University, Hyderabad, India, in 2010, The M.Tech. Degree in power and Energy systems from the National Institute of Technology Karnataka, Surathkal, India in $2012 \mathrm{He}$ is currently Working as a Asst.Execuitive Engineer (Electrical) ,Power Electronics \& Automation division in Neyveli Lignite Corporation Ltd ,Tamilnadu,India. His research interests are Power electronics and Automation of multilevel inverters, PI current control techniques, photovoltaic inverters, and dc-dc converters. 